\title{
Análise ergonômica do trabalho em unidades de beneficiamento de produtos agrícolas: exigências laborais dos postos de seleção
}

\author{
Ergonomic work analysis in agricultural products packinghouses: \\ job demands of the selection workplaces
}

\author{
Celso de Oliveira Braga ${ }^{I *}$ Roberto Funnes AbrahãoI Mauro José Andrade Tereso
}

\section{RESUMO}

O beneficiamento pós-colheita é uma atividade em grande expansão no Brasil. Neste estudo adotou-se a abordagem ergonômica para analisar as exigências laborais em unidades de beneficiamento de tomate de mesa (UB). Aplicou-se o método da Análise Ergonômica do Trabalho para identificar os postos de trabalho de maiores exigências laborais. $\mathrm{Na}$ pesquisa de campo envolvendo 61 operadores, foram utilizados o Método NASA TLX e o Questionário de Avaliação Visual. A exigência mental foi elevada nos postos de trabalho de bicas e seleção. A exigência visual foi elevada nas UB de baixos níveis de iluminância, e a exigência física foi alta nos postos de alimentação de todas UB e nas bicas das UB que não contavam com auxílio mecânico para movimentação de caixas.

Palavras-chave: ergonomia, tomate, fadiga mental, cognição, unidade de beneficiamento.

\section{ABSTRACT}

The post harvest processing is an activity in large expansion in Brazil. In this research, the ergonomic approach was adopted to analyze the job demands in fresh tomato packinghouses. The Ergonomic Work Analysis Method was adopted to identify the workplaces with the leading job demands. In the field research involving 61 workers, it was applied the NASA TLX method and the Visual Assesment Questionnaire. The mental demand was high at the selection and outlet workplaces. It was detected high visual demand in packinghouses with low illuminance levels as well as the physical demand at the loading cells workplaces in all the packinghouses and at the outlet workplaces in the packinghouses without mechanical help for the moving of the boxes.

Ke words: ergonomics, NASA TLX, tomato cropping, fatigue.

\section{INTRODUÇÃO}

A maioria dos estudos disponíveis na literatura técnica sobre unidades de beneficiamento de produtos agrícolas (UB) refere-se a pesquisas voltadas ao produto, à produtividade e à qualidade, sendo os estudos dos riscos ocupacionais e das exigências laborais ainda raros no Brasil. Segundo FERREIRA (2003), o tomate de mesa ou in natura até pouco tempo era classificado no campo, diretamente na lavoura. Atualmente o processo de seleção e classificação de tomate é realizado em unidades de beneficiamento, que se caracterizam pela adoção de diferentes tecnologias, formas de organização do trabalho e volumes de produção. CORTEZ et al. (2002) e FERREIRA (2003) descrevem as operações básicas do processo de beneficiamento como sendo o descarregamento ou recebimento, alimentação da esteira, seleção, limpeza ou toalete, classificação, embalagem, pesagem, unitização ou paletização, resfriamento, armazenamento, carregamento e transporte.

A abordagem ergonômica do trabalho nas UB permite o conhecimento dos fatores intervenientes na carga de trabalho dos operadores, buscando-se compreender a relação entre os determinantes da tarefa e os níveis das exigências laborais (GRANDJEAN, 1998). A hipótese geral apresentada neste este trabalho é que a configuração inadequada das tarefas nas UB, em particular em seus aspectos ambientais, tecnológicos e organizacionais, propicia a ocorrência de fadiga mental, física e visual nos operadores.

'Faculdade de Engenharia Agrícola (Feagri), Universidade Estadual de Campinas (Unicamp), 13083-970, Campinas, SP, Brasil. Email: mauro@agr.unicamp.br. *Autor para correspondência. 
Nesta pesquisa aplicou-se o conceito de carga de trabalho, que representa o custo para o operador conseguir um determinado nível de rendimento ou um resultado concreto. É também definido como o resultado da interação entre os requisitos da tarefa e as circunstâncias em que ela se desenvolve, as capacidades, condutas, sensações e percepções do trabalhador (MORAY,1988).

Todas as atividades compreendem exigências físicas e mentais e cada uma delas provoca uma carga de trabalho. A avaliação da carga de trabalho deve ser realizada em situação real de trabalho (WISNER, 1987).

Segundo DANIELLOU et al. (2004), a Análise Ergonômica do Trabalho permite compreender o trabalho para depois transformá-lo. Esse método é composto de três fases: a análise da demanda, a análise da tarefa e a análise da atividade. A análise da demanda consiste em definir o problema a ser analisado, delimitar o objeto de estudo e esclarecer suas finalidades. A análise da tarefa corresponde ao levantamento dos dados referentes aos objetivos e resultados que se espera do trabalho e os meios disponíveis para realizálo. Já a análise da atividade consiste em compreender o trabalho que é efetivamente realizado, as dificuldades encontradas e as estratégias utilizadas para enfrentálas.

A carga mental reúne os aspectos psíquicos e cognitivos da tarefa, constituindo-se numa função complexa e pessoal. A carga psíquica refere-se às cargas relacionadas à interação afetiva entre o trabalhador e seu trabalho ou à significação do trabalho para quem o faz. A carga cognitiva refere-se à interação do trabalhador com uma tarefa ou um equipamento nos aspectos informacionais e de tomada de decisão, relacionando-se ao uso da memória, às decisões e ao raciocínio (BRIDGER, 1995).

Um estudo realizado na Alemanha por JAHN et al. (2005) mediu a carga de trabalho de motoristas, focando-se nas tarefas de detecção periférica. O método NASA TLX foi empregado na avaliação da carga mental de 49 motoristas para mensurar a sensibilidade deles em relação às demandas das rotas.

OTMANI et al. (2005) aplicaram o método NASA TLX para medir o efeito da idade e da hora do dia na sonolência de motoristas profissionais. A demanda surgiu de dados do National Highway Traffic Safety Administration dos Estados Unidos da América que demonstraram ser a fadiga e a sonolência responsáveis por $15 \%$ dos acidentes fatais. Concluiuse que os motoristas profissionais adormecem ao volante, especialmente à noite, por causa de jornadas excessivas de longas horas.
FRANCE et al. (2005) empregaram o instrumento NASA TLX para estudar melhorias na organização do trabalho, no acesso às informações do sistema e nos agendamentos de atendimentos clínicos a fim de gerenciar o trabalho de médicos de forma segura e eficiente. O NASA TLX foi utilizado para medir a carga de trabalho subjetiva ao final de cada observação médica.

Este trabalho procurou conhecer a composição da carga de trabalho e seus efeitos sobre os trabalhadores em UB. Para identificação dos postos de trabalho com as maiores exigências laborais, empregou-se parcialmente o Método da Análise Ergonômica do Trabalho (AET). Na análise dessas exigências, para a avaliação das cargas de trabalho mental e física e para a avaliação da carga visual, foram utilizados, respectivamente, o Método NASA TLX e o Questionário de Avaliação Visual (QAV).

\section{MATERIAL E MÉTODOS}

Foram selecionadas seis UB localizadas no Estado de São Paulo a partir de uma amostragem intencional em função dos diferentes níveis tecnológicos dos equipamentos, das diferentes instalações, dos volumes de produção e das formas de organização do trabalho. Realizou-se um estudo-piloto na UB1 que se prestou a uma primeira abordagem das situações de trabalho e a uma aproximação ao objeto de estudo.

O Método da Análise Ergonômica do Trabalho (AET) foi empregado de forma parcial. Foi feita uma coleta de dados gerais sobre os trabalhadores e sobre o funcionamento da empresa. Os trabalhadores foram entrevistados e realizaram-se observações abertas e sistemáticas das atividades laborais, com filmagens e fotos. A análise desses dados permitiu identificar os postos de trabalho de seleção e de operação das bicas de saída como os de maiores exigências laborais, caracterizados por cargas de trabalho perceptuais e cognitivas, típicas das tarefas de inspeção, além de cargas físicas e visuais. O posto de alimentação da esteira foi escolhido como contraponto aos de seleção e operação de bicas, por exigir esforço predominantemente físico.

O Método NASA TLX (HART et al., 1988) foi utilizado na avaliação das cargas física e mental dos operadores nas UB. Ele dispõe de seis escalas correspondentes: aos níveis de realização, esforço e frustração (influenciados pelas características individuais dos operadores); e aos níveis de exigências mental, física e temporal (determinados pela situação de trabalho). Pergunta-se diretamente ao operador qual 
a sua sensação sobre cada um deles. Dentre os seis fatores, a exigência mental (EM) e a exigência física (EF) foram os únicos de interesse para esta pesquisa. Foram entrevistados 57 operadores dos postos de seleção, alimentação da esteira e de bicas. Para cada fator avaliado, o operador indicou um valor entre 0 (zero) e 100 (cem) correspondente à sua sensação ou sua percepção subjetiva dos níveis de dificuldades encontrados na realização da atividade. Cada entrevistado respondeu a 15 perguntas de comparação entre pares desses fatores, para apontar aqueles que tiveram maior peso na sua carga de trabalho. Essa segunda parte do instrumento NASA TLX é formada por um software desenvolvido pela NASA.

Neste estudo, a escala de 0 a 100 (cem) do NASA TLX foi dividida em três faixas: valores baixos (de 0 a 33,0); valores médios (de 33,1 a 66,0) e valores altos (de 66,1 a 100). Também foi desenvolvido e aplicado um Questionário de Avaliação Visual (QAV) por meio do qual os operadores expressaram suas sensações sobre os sintomas oculares, visuais e gerais, bem como os sinais comportamentais e as atitudes que fazem para minimizar o desconforto visual. O questionário foi construído com base na Escala de Likert modificada (KARASEK\&THEORELL,1990). Para as alternativas de respostas às questões formuladas, foram atribuídos pesos de zero a três. Como eram 24 itens avaliados, a somatória de cada questionário correspondia a valores compreendidos entre 0 (zero) e 72 (setenta e dois) pontos. Posteriormente, as escalas foram calculadas pelas médias dos questionários por posto de trabalho. Neste estudo, essa escala também foi dividida em três faixas: valores baixos (de 0 a 23); valores médios (de 23,1 a 46); e valores altos (de 46,1 a 72).

Na comparação simultânea dos dados obtidos para as exigências laborais, utilizou-se o teste de Kruskal-Wallis. Para as comparações múltiplas (pares de grupos), realizou-se o teste de StudentNewman-Keuls (SNK). Foi utilizado o software SAS, versão 8.

\section{RESULTADOS E DISCUSSÃO}

O estudo-piloto feito na UB1 mostrou que o processo de beneficiamento tinha início com a chegada do caminhão carregado com caixas de tomates. Em seguida, eram realizados os processos de descarga e armazenamento das caixas no galpão. A próxima etapa, chamada de alimentação da esteira, consistia na virada ou no tombamento das caixas de tomate na entrada da esteira. O número de operadores nesse posto de trabalho variou de um a três nas UB estudadas. Na seqüência, no posto de seleção, os tomates eram selecionados manualmente, retirando-se os defeituosos ou fora do padrão e empregando-se de um até quatro operadores. Os tomates descartados eram lançados em uma canaleta e seguiam por gravitação para caixas plásticas (para fabricação de molho ou massa de tomate ou venda aos feirantes e pequenos comerciantes).

A etapa seguinte consistia na lavagem por meio de um gotejador, utilizando-se o mínimo possível de água para evitar a contaminação dos frutos por fungos e bactérias. Seguia-se a etapa de secagem e polimento dos tomates. Depois, era feita a classificação automática, processo em que um equipamento constituído de câmeras para inspeção visual automática e um computador (com software específico) classificava os tomates pelo tamanho e pela cor. Depois de selecionados, os tomates seguiam para as bicas de saída, onde os frutos eram depositados em caixas plásticas, de madeira ou de papelão. Essas caixas eram pesadas e paletizadas (postos de pesagem e paletização). Havia uma bica especial destinada aos tomates não reconhecidos pela classificação automática, chamada de bica de descarte.

Ao final do processo, executava-se a limpeza dos equipamentos e do galpão. Algumas UB dispunham de equipamentos para lavagem de caixas, para montagem de caixas de papelão, empilhadeiras elétricas ou a gás para carregamento ou descarregamento dos paletes nos caminhões.

A análise das verbalizações dos operadores obtidas por meio de entrevistas revelou a ocorrência de dores na nuca, na cabeça, nos olhos, nas pernas e nos pés, além de dificuldades relacionadas ao volume da produção, ao ritmo de trabalho, à precária distribuição das tarefas, ao projeto e layout dos galpões, às características ambientais e à tecnologia adotada nas UB. A tabela 1 apresenta dados referentes às UB estudadas.

A tabela 2 apresenta os valores médios da exigência física (EF), obtidos nos três postos de trabalho, com a aplicação do método NASA TLX aos 57 operadores das UB. Os valores baixos estão marcados em verde, os valores médios, em amarelo e os valores altos, em vermelho.

Nas bicas, a exigência física depende da existência ou não de auxílio mecânico na movimentação das caixas e da quantidade de operadores. Nesse posto todos os valores resultaram abaixo de 60 , exceto na UB2, onde a tecnologia do equipamento é inadequada e o volume de produção é alto. Os resultados da análise pelo teste de Kruskal-Wallis, obtidos na comparação da exigência física no posto de bicas das seis diferentes UB, ao nível de significância de 5\%, mostraram que não houve diferença significativa entre a UB1 e UB4 e entre a UB5 e UB6. Estatisticamente, a UB2 e UB3 são diferentes das demais, com diferenças significativas de exigência física.

Ciência Rural, v.39, n.5, ago, 2009. 
Tabela 1 - Características das Unidades de Beneficiamento (UB).

\begin{tabular}{|c|c|c|c|c|c|c|}
\hline Parâmetros e características & UB1 & UB2 & UB3 & UB4 & UB5 & UB6 \\
\hline $\mathrm{N}^{\mathrm{o}}$ de operadores & 10 & 13 & 17 & 07 & 14 & 12 \\
\hline Produção Caixas/mês & 8.000 & 163.800 & 458.640 & 4.800 & 131.040 & 112.320 \\
\hline Iluminância Bicas (lux) & 250 & 160 & 880 & 790 & 800 & 210 \\
\hline Iluminância Seleção (lux) & 240 & 480 & 813 & 520 & 615 & 450 \\
\hline Iluminância Alimentação (lux) & 230 & 190 & 521 & 430 & 600 & 290 \\
\hline No de linhas de classificação & 03 & 06 & 06 & 03 & 04 & 02 \\
\hline $\begin{array}{l}\text { Galpão projetado, adaptado ou } \\
\text { parcialmente projetado }\end{array}$ & Adaptado & Adaptado & Projetado & Adaptado & $\begin{array}{l}\text { Parcialmente } \\
\text { Projetado }\end{array}$ & $\begin{array}{l}\text { Parcialmente } \\
\text { Projetado }\end{array}$ \\
\hline Layout da linha de beneficiamento & linha reta & linha reta & linha reta & em L & em E & linha reta \\
\hline
\end{tabular}

No posto de alimentação da esteira, os valores de exigência física foram elevados. Os operadores executam o tombamento das caixas cheias de tomates na entrada da esteira, exceto nas UB2 e UB5, que adotaram tecnologias apropriadas para o tombamento das caixas, diminuindo o esforço físico exigido nesse posto (esteira com roletes e mecanização do tombamento, respectivamente). Como as demais UB não dispunham de mecanismos de auxílio ao tombamento, os valores de exigência física mostraramse elevados. Estatisticamente não houve diferença significativa entre a UB1 e UB4 e entre a UB5 e UB6.

No posto de seleção, não houve exigência física elevada porque não há movimentação de caixas. As UB não diferem estatisticamente quanto à exigência física. Onze dos 16 operadores da seleção apontaram baixa exigência física para a atividade, correspondente a $69 \%$ dos trabalhadores desse posto.

A tabela 3 apresenta os valores médios obtidos para a exigência mental (EM) nos três postos de trabalho. As médias obtidas para o posto das bicas, nas UB1, UB4, UB5 e UB6, revelaram elevada exigência mental, com valores estatisticamente iguais. Para as UB1 e UB6, os altos valores de exigência mental nas bicas ocorrem devido ao baixo nível de iluminância (ver Tabela 1). Já para as UB4 e UB5, a ausência de auxílio mecânico na movimentação das caixas no posto de bicas influenciou os altos valores obtidos para exigência mental. As observações sistemáticas da atividade nesses postos revelaram que os operadores realizavam muitas operações ao mesmo tempo (observavam o enchimento das caixas e movimentavam-nas para

Tabela 2 - Valores médios obtidos para a exigência física (EF) nas UB.

\begin{tabular}{lcccccc}
\hline POSTO & UB1 & UB2 & UB3 & UB4 & UB5 & UB6 \\
\hline Bicas & 36,0 & 81,0 & 23,0 & 36,3 & 45,0 & 58,0 \\
Seleção & 41,3 & 30,0 & 30,0 & 27,5 & 32,5 & 25 \\
Alimentação & 95,0 & 33,3 & 76,7 & 95,0 & 45,0 & 67,5 \\
\hline
\end{tabular}

pesagem e colocação nos paletes simultaneamente às operações de seleção), o que também influenciou os valores de exigência mental elevados para essas UB.

Na UB3, que apresentou o menor valor médio para as exigências mentais e físicas nas bicas, os operadores apenas observavam o enchimento das caixas e as empurravam para uma esteira que as conduzia às equipes de pesagem e paletização, o que tornava o trabalho menos complexo. O menor valor médio para exigência mental verificado na UB3 ocorreu em função do fator organizacional do trabalho (colocação de equipes diferenciadas de operadores para bicas, pesagem e paletização), do fator tecnológico (três linhas de produção com equipamentos distintos para execução do processo de beneficiamento) e do fator ambiental (galpão projetado e construído para ser utilizado como UB com índices de iluminância adequados).

No posto de seleção, houve predominância da exigência mental (EM) sobre a exigência física, pois essa atividade utiliza essencialmente os recursos cognitivos e perceptuais dos operadores. Os seguintes agrupamentos: as UB1 e UB2; as UB3, UB4 e UB6; e as UB4, UB5 e UB6 constituíram valores estatisticamente iguais para os níveis de exigência mental. Já para o posto de alimentação, os valores obtidos para a exigência mental foram os mais baixos, uma vez que aqui a atividade é predominantemente física.

A tabela 4 apresentou os valores médios da exigência visual (EV) nos postos de trabalho das bicas, de seleção e de alimentação da esteira, obtidos com a aplicação do Questionário de Avaliação Visual (QAV).

Tabela 3 - Valores obtidos para a exigência mental (EM) nas UB.

\begin{tabular}{lcccccc}
\hline POSTO & UB1 & UB2 & UB3 & UB4 & UB5 & UB6 \\
\hline Bicas & 90,0 & 64,0 & 26,0 & 91,3 & 87,5 & 84,0 \\
Seleção & 80,0 & 85,0 & 35,0 & 50,0 & 57,5 & 45,0 \\
Alimentação & 20 & 15,0 & 28,3 & 20,0 & 37,5 & 37,5 \\
\hline
\end{tabular}


Tabela 4 - Resultados das avaliações da exigência visual (EV) nas UB.

\begin{tabular}{lcccccc}
\hline POSTO & UB1 & UB2 & UB3 & UB4 & UB5 & UB6 \\
\hline Bicas & 40 & 40 & 6 & 6 & 12,8 & 6 \\
Seleção & 54 & 54 & 9 & 20 & 26 & 20 \\
Alimentação & 42 & 42 & 6 & 6 & 6 & 6 \\
\hline
\end{tabular}

Em todos os postos avaliados (alimentação, seleção e bicas), a exigência visual foi baixa nas UB3, UB4 e UB5, correspondendo aos maiores índices de iluminância (ver Tabela 1). Por seu turno, também em todos os postos, as UB1 e UB2, com os piores índices de iluminância nas bicas e na seleção, registraram índices médios mais elevados de exigência visual.

Cabe ressaltar que o galpão da UB3 foi projetado e, dessa forma, os fatores ambientais, como a iluminação e a ventilação natural, foram levados em conta para assegurar boas condições de trabalho. Já as UB4, UB5 e UB6 são galpões adaptados, com a instalação de janelões e/ou a colocação de telhas transparentes no teto. Os valores obtidos nas exigências visuais nessas três UB refletem claramente essas condições.

Estatisticamente, para os três postos, a exigência visual apresentou diferença significativa entre o grupo constituído pelas UB1 e UB2 e o grupo formado pelas UB3, UB4, UB5 e UB6. Entre 61 operadores estudados nos três postos de trabalho das seis UB, constatou-se que 10 deles, ou seja, a totalidade dos operadores das UB1 e UB2, correspondendo a $16,3 \%$ do total de operadores avaliados, apontaram valores de exigência visual elevada, revelando situações de trabalho que oferecem risco de fadiga visual.

A figura 1 apresenta os valores de exigência física (Figura 1A), mental (Figura 1B) e visual (Figura 1C) nos postos de alimentação, seleção e bicas, independentemente das UB. Os resultados da análise pelo teste de Kruskal-Wallis e Student-Newman-Keuls (SNK) mostraram que, com relação às exigências física, mental e visual, todos os postos mencionados anteriormente são estatisticamente diferentes. Como esperado, os maiores valores de exigência física foram exibidos pelos postos de alimentação, seguidos do posto de bicas e finalmente do posto de seleção. Com relação à exigência mental, a ordenação decrescente revela primeiramente o posto de bicas seguido dos postos de seleção e alimentação. O resultado alcançado pelo posto de bicas é uma conseqüência da grande variedade de operações executadas nesse local. No que concerne à exigência visual, apresentada em ordem decrescente de valores, destaca-se o posto de seleção,

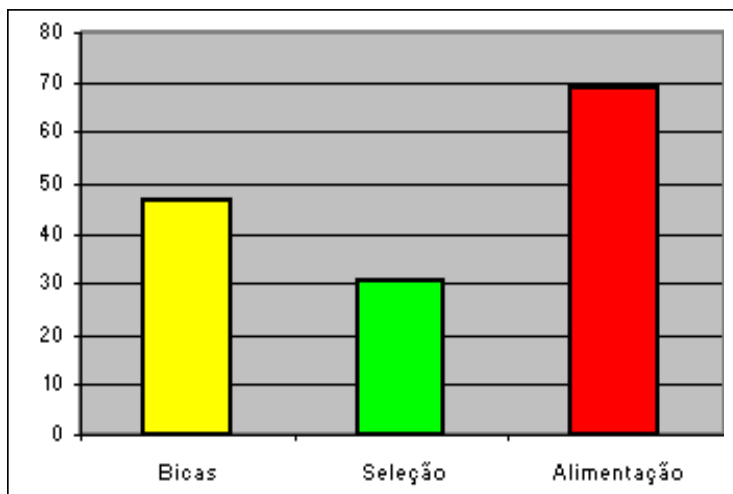

A) Exigência·Física
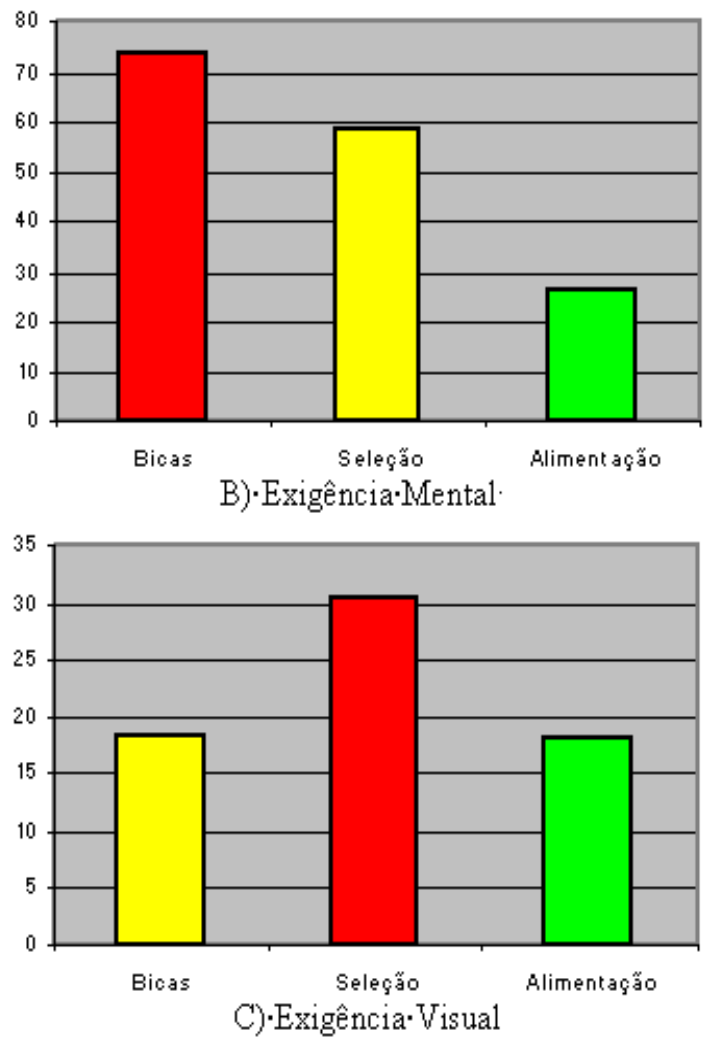

Figura 1 - Resultados do NASA TLX e do Questionário de Avaliação Visual.

seguido dos postos de bicas e de alimentação da esteira. A necessidade de se manter um elevado grau de atenção, aliada ao grande volume de estímulos visuais, constituem a causa dos elevados valores de exigência visual dos postos de seleção.

\section{CONCLUSÕES}

Este trabalho revelou a relação existente entre o nível de exigência física, mental e visual dos postos de alimentação, seleção e operação de bicas

Ciência Rural, v.39, n.5, ago, 2009. 
nas UB e os fatores determinantes das tarefas, em particular fatores ambientais (nível de iluminância dos postos de trabalho), tecnológicos (dispositivos de auxílio mecânico à movimentação de caixas) e organizacionais (número de operadores alocados nas tarefas).

A exigência mental mostrou-se mais elevada nos postos de operação de bicas em função da quantidade de operações que devem ser cumpridas pelos operadores. Já a exigência visual, como esperado, revelou-se mais intensa nos postos de seleção em função da natureza da tarefa, caracterizada por maiores exigências cognitivas e perceptuais.

Podem ser sugeridas as seguintes recomendações para a melhoria das condições de trabalho nas UB estudadas: empregar mecanização no posto de alimentação da esteira para a virada ou o tombamento das caixas, como adotado na UB5 ou sistema de bancada com roletes a uma altura adequada para reduzir os esforços dos operadores, como existente na UB2; evitar a situação de sobrecarga fisica existente nos postos de alimentação das UB1, UB3, UB4 e UB6, onde um único operador executa as operações de pegar, virar e empilhar as caixas vazias ao lado da esteira; instalar banquetas de altura ajustável nos postos de seleção, de forma a possibilar ao operador a alternância entre as posições sentado ou em pé durante a execução da atividade; adequar o nível de iluminância nos postos de seleção e nas bicas (no mínimo 700 lux, conforme preconizado pela NR-15) para evitar a fadiga visual; alocar a quantidade necessária de operadores nos postos de seleção para não sobrecarregar os operadores de bicas; instalar esteira rolante nos postos de operação de bicas para condução das caixas cheias até a pesagem, para evitar a sobrecarga de trabalho dos operadores.

\section{AGRADECIMENTOS}

Os autores agradecem ao Fundação de Apoio ao Ensino, à Pesquisa e à Extensão (FAEPEX), pelo apoio financeiro.

\section{REFERÊNCIAS}

BRIDGER, R.S. Introduction to ergonomics: cognitive ergonomics problem solving and decision making. Nova York: McGraw-Hill, 1995. 576 p.

CORTEZ, L.A.B. et al. Resfriamento de frutas e hortaliças. Brasília: Embrapa Informação Tecnológica, 2002. 428p.

DANIELlOU, F. et al. A ergonomia em busca de seus princípios: debates epistemológicos. São Paulo: Edgard Blücher, 2004. 200p

FERREIRA, M.D. Perdas na cadeia produtiva do tomate de mesa. In: WORKSHOP TOMATE NA UNICAMP, 2003, Campinas-SP. Anais... Campinas: UNICAMP, 2003. CDRom.

FRANCE, D.J. et al. Emergency physicians' behaviors and workload in the presence of an electronic whiteboard. International Journal of Medical Informatics, v.74, p.827-837, 2005. Disponível em: <http:/ /www.sciencedirect.com/science?_ob=ArticleURL\&_udi=B6T7S4GPW3TS-1\&_user $=687358 \&$ _rdoc $=1 \&$ \&mt $=\&$ \&orig $=$ search \&_sort $=\mathrm{d} \&$ view $=$ c\&_acct $=\mathrm{C} 000037899 \&$ _version $=1 \&$ \&_urlVersion $=0$ \&_userid=687358\&md 5=de2be9a7a7064f65dd75f7e9d636d1db>. Doi: 10.1016/j.ijmedinf.2005.03.015.

GRANDJEAN, E. Manual de ergonomia - adaptando o trabalho ao homem. 4.ed. São Paulo: Artmed, 1998. 327p.

HART, S.G.; STAVELAND, L.E. Development of NASA-TLX (Task Load Index): results of empirical and theoretical research. In: MESHKATI, N. (Ed.). .Human mental workload. Amsterdam: North-Holland, 1988. p.139-183.

JAHN, G. et al. Peripheral detection as a workload measure in driving effects of traffic complexity and route guidance system use in a drive study. Transportation Research Part F v.8, p. 255-275, 2005

MORAY, N. Mental workload since 1979. International Reviews of Ergonomics, .2, p.123-150, 1988.

OTMANI, S.; ROGÉ, J.; MUZET, A. Sleepiness in professional drivers: effects of age and time of day. Accident analysis and prevention, v.37, n.5, p.930-937, 2005

WISNER, A. Por dentro do trabalho: ergonomia, método \& técnica. São Paulo: FTD/Oboré, 1987. 189p. 